\title{
Desafios para garantia do direito à participação de crianças e adolescentes no sistema judicial brasileiro ${ }^{1}$
}

Challenges to assure rights of children and adolescents to take part in the Brazilian judicial

system

\section{Helen Crystine Corrêa Sanches*}

\begin{abstract}
RESUMO: O artigo analisa o conteúdo do direito à participação de crianças e adolescentes nos processos ou procedimentos que lhes afetem, sob o marco da Doutrina da Proteção Integral. Inserindo-se no contexto amplo de liberdade de opinião, expressão e informação, o exercício do direito à participação implica no reconhecimento da autonomia progressiva da criança e do adolescente, de acordo com as circunstâncias do caso em concreto, superando-se as limitações relativas à capacidade civil. A falta de regras procedimentais específicas na prática judiciária justifica a necessidade de reflexão sobre os desafios a serem superados para sua garantia efetiva.
\end{abstract}

PALAVRAS-CHAVE: Criança; Adolescente; Doutrina da Proteção Integral; Direito à participação; Autonomia progressiva; Capacidade civil; Sistema de Justiça.

ABSTRACT: The article analyzes the content of the right to participation of children and adolescents in processes or procedures affecting them, under the framework of the "Doutrina da Proteção Integral". Entering in the broader context of freedom of opinion, expression and information, the exercise of the right to take part implies the recognition of the child and adolescent progressive autonomy, according to the circumstances of the case, overcoming the limitations relating to civil capacity. The lack of specific procedural rules on judicial practice justifies the need for reflection on the challenges to overcome its effective enforcement.

KEYWORDS: Child; Adolescents; "Doutrina da Proteção Integral"; Right to participate; Progressive autonomy; Civil capacity; Justice System.

\section{INTRODUÇÃO}

A necessidade de controle e disciplinamento da infância na história ocidental forjou o contexto cultural no qual se habita a pensar crianças como seres passivos, destinatários da ação dos adultos, sem opinião ou vontade própria. O processo evolutivo de afirmação e especificação dos direitos da criança, conferindo-lhe uma proteção especial e particularizada, em face de sua própria vulnerabilidade, a partir do século $\mathrm{XX}$, levou ao reconhecimento da necessidade, e, mais, além disso, do seu direito de participar da vida coletiva.

\footnotetext{
${ }^{1}$ Artigo baseado na tese intitulada "Da vara de menores à vara da infância e juventude: desafios para a proteção integral dos direitos de crianças e adolescentes no Sistema de Justiça brasileiro" (SANCHES, Helen Crystine Corrêa. Tese (Doutorado em Direito). Universidade Federal de Santa Catarina, Florianópolis, 2014).

* Doutora em Direito pela Universidade Federal de Santa Catarina (UFSC). Promotora de Justiça do Estado de Santa Catarina. E-mail: helenccsanches@ gmail.com. Data de recebimento do artigo: 15/01/2016 - Data de avaliação: 20/01/2016 e 01/02/2016.
} 
Desafios para garantia do direito à participação de crianças e adolescentes no sistema judicial brasileiro

Nesta perspectiva é que se permite focalizar um conjunto de representações sociais sobre a infância que se construíram ao longo da história e que, ao traduzir-se em práticas sociais concretas, dificultam o reconhecimento pleno de crianças e adolescentes como sujeitos de direitos, partindo da ideia de adulto como paradigma, no que resulta em considerar seus direitos como secundários ou restritos, sobre os quais os adultos têm uma autoridade arbitrária.

Inaugurando o paradigma jurídico da proteção integral, a Convenção sobre os Direitos da Criança consagrou um conjunto de direitos relativos à participação de crianças e adolescentes, estabelecendo em seu artigo 12 que os Estados assegurarão àquela que estiver capacitada a formular seus próprios juízos o direito de expressar suas opiniões livremente sobre todos os assuntos a eles relacionados, levando-se devidamente em consideração essas opiniões, em função da sua idade e maturidade, garantindo-se, com tal propósito, a oportunidade de ser ouvida em todo processo judicial ou administrativo que lhe afete.

Esse reconhecimento de que crianças são atores sociais, ou seja, sujeitos com capacidade de ação e interpretação sobre suas escolhas e decisões, é ainda um desafio na implementação do seu direito à participação, seja na vida coletiva, por meio da participação política, seja no âmbito individual, nos espaços familiar, institucional ou judicial.

No âmbito do Sistema de Justiça brasileiro, a não efetividade e as dificuldades na garantia do direito de crianças e adolescentes serem ouvidos nos processos que lhes afetem, como vítima, testemunha ou como terceiro interessado, constitui-se em indicador seguro das limitações decorrentes da necessária transposição das práticas jurídicas que operam apenas parcialmente o modelo implementado pela Doutrina da Proteção Integral, consagrada constitucionalmente, que vincula o seu exercício à sua afirmação como sujeito de direitos.

A necessidade de detalhamento do conteúdo referente à garantia desse direito implica na necessidade do Sistema de Justiça em enfrentar questões não abrangidas no texto convencional para colocá-lo em prática esse direito, já que a Convenção sobre os Direitos da Criança não estabelece os parâmetros para sua operacionalização.

Para tanto, é necessário reconhecer o direito à autonomia progressiva da criança e do adolescente, superando-se a concepção atrelada aos critérios de capacidade previstos na legislação civil, garantindo-se, em todo procedimento administrativo ou judicial, a sua oitiva obrigatória e a participação nos atos e na definição da medida a ser adotada, como 
expressamente dispõe o princípio elencado no art. 100, parágrafo único, inciso XII, do Estatuto da Criança e do Adolescente, acrescentado pela Lei n. 12.010, de 3 de agosto de 2009.

Tais desafios tem como pressuposto a superação das dificuldades relacionadas às respectivas implicações procedimentais, examinadas sob a perspectiva do enfrentamento de questões não abrangidas na legislação pátria e da prática judicial forense para garantia da participação da criança e do adolescente no processo e da defesa dos seus interesses manifestos, notadamente nos casos de violação de direitos.

\section{A CRIANÇA E O ADOLESCENTE COMO SUJEITO DE DIREITOS: AUTONOMIA PROGRESSIVA VERSUS CAPACIDADE CIVIL}

Reconhecendo expressamente as crianças como sujeitos em desenvolvimento, a Convenção sobre os Direitos da Criança assume a particularidade da infância e da adolescência em virtude da falta de maturidade física e mental, atribuindo-lhes o caráter de um sujeito jurídico especial, com "autonomia progressiva" para o exercício dos direitos, de acordo com a avaliação de sua capacidade ${ }^{2}$.

Correspondendo a um direito à participação propriamente dita, o reconhecimento dessa autonomia progressiva para o exercício pessoal dos seus direitos pela Convenção sobre os Direitos da Criança, em um processo de desenvolvimento e evolução das suas capacidades, estabelece a obrigação do Estado e dos adultos em garantir os meios e recursos necessários para que possam posicionar-se ${ }^{3}$.

Para isso, é essencial superar-se a concepção atrelada aos critérios de capacidade previstos na legislação civil, a fim de que a garantia dos direitos de crianças e adolescentes tenha como premissa o reconhecimento de suas competências subjetivas e jurídicas, para que possam assumir posições jurídicas na sociedade (MELO, 2011, p. 46).

Para tanto, é fundamental ter presente o quanto a capacidade de ação por parte de crianças e adolescentes está limitada por toda uma estruturação histórica de concepção de autonomia e dos direitos subjetivos fundados em referenciais

\footnotetext{
${ }^{2}$ Artigo 5. Os Estados Partes respeitarão as responsabilidades, os direitos e os deveres dos pais ou, onde for o caso, dos membros da família ampliada ou da comunidade, conforme determinem os costumes locais, dos tutores ou de outras pessoas legalmente responsáveis, de proporcionar à criança instrução e orientação adequadas e acordes com a evolução de sua capacidade no exercício dos direitos reconhecidos na presente convenção.

${ }^{3}$ Para Miguel Cillero Bruñol (1999), a Convenção sobre os Direitos da Criança reconhece em seu artigo $5^{\circ}$, o que denomina de "princípio da autonomia progressiva" da criança no exercício de seus direitos.
}

RJurFA7, Fortaleza, v. 12, n. 2, p. 10-32, jul./dez. 2015 
Desafios para garantia do direito à participação de crianças e adolescentes no sistema judicial brasileiro

\begin{abstract}
adultocêntricos, racionais, de que crianças e adolescentes não seriam detentores por completo. A referência à própria concepção de 'desenvolvimento' aludida por Foucault é retrato disto. Por isso, não basta a afirmação de que se é sujeito de direito. Precisa-se compreender de modo distinto como reconhecer as competências jurídicas através da legitimação da participação social de crianças e adolescentes, pelo reconhecimento de suas competências sociais (MELO, 2011, p. 46-47).
\end{abstract}

O regime das incapacidades para o exercício pessoal de determinados direitos, previsto nas normas civis ${ }^{4}$, em face da ausência de discernimento ou imaturidade dos doentes psíquicos e os menores de determinada idade, tendo como finalidade precípua o intuito de resguardar o patrimônio do incapaz e a segurança das relações jurídicas, dificultou o reconhecimento de que seus interesses deveriam subordinar a família, sociedade e o Estado.

Questionando essa perspectiva, que caracteriza como negativista, redutora e embasada em um adultocentrismo patrimonialista, Josiane Rose Petry Veronese (2012, p. 83) indaga ainda se não estaria esse sujeito de direitos sendo gradativamente sentenciado ao taxativo sinônimo de "negação" individual e social, reduzido à não-capacidade, à não-suficiência, à não-maturidade e, consequentemente, à não-eficiência, com graves repercussões decorrentes do efeito dos preconceitos negativos sobretudo naquele que se encontra no "ápice da formação do autoconceito".

Dessa perspectiva, a limitação ao exercício dos direitos de que são titulares crianças e adolescentes, não pode ser concebida, portanto, a partir dos critérios relativos à capacidade fixados na legislação civil, sob pena de negar-se a sua própria condição de sujeito em processo de desenvolvimento. Do ponto de vista dos direitos fundamentais, os critérios estabelecidos na legislação civil não podem suprimir ou restringir o exercício de qualquer direito de que a criança seja titular, mesmo contrário aos interesses de seu representante.

Consequentemente, esse excesso de proteção não pode redundar na supressão do exercício dos direitos personalíssimos e da promoção da autonomia conferida à criança, como condição de seu próprio desenvolvimento, pois,

Se a autonomia (rectius, a liberdade individual) é fundamental para a constituição do
sujeito como pessoa, será que poderíamos aplicar irrestritamente o regime das
incapacidades para a criança e ao adolescente, ou eles poderiam ter resguardados
espaços de autonomia, no que tange, principalmente, ao exercício de direitos
personalíssimos? Seria possível alargar os confins da autonomia para aquele que

\footnotetext{
${ }^{4}$ De acordo com o Código Civil Brasileiro (Lei n. 10.406, de 10 de janeiro de 2002), os menores de dezesseis anos são absolutamente incapazes de exercer pessoalmente os atos da vida civil (art. $3^{\circ}$, I) e são incapazes, relativamente a certos atos, ou à maneira de exercê-los, os maiores de dezesseis e menores de dezoito anos (artigo $\left.4^{\circ}, \mathrm{I}\right)$.
}

RJurFA7, Fortaleza, v. 12, n. 2, p. 10-32, jul./dez. 2015 
embora não tenha alcançado a maioridade, seja dotado de discernimento quando estão em jogo seus interesses? (TEIXEIRA et al, 2008, p. 344).

A avaliação da capacidade de entendimento da criança, de acordo com sua etapa de desenvolvimento, deve ser avaliada em cada caso concreto para orientar as medidas a serem adotadas, garantindo-lhe o direito de ser ouvido e que sua opinião seja obrigatoriamente considerada, como estabelece o artigo 12 da Convenção sobre os Direitos da Criança, superando-se a dicotomia entre a capacidade de direito e a capacidade de fato, como observa Pietro Perlingieri (2007, p. 260):

[...] é necessário superar a rígida separação, que se traduz em uma fórmula alternativa jurídica, entre minoridade e maioridade, entre incapacidade e capacidade (retro, cap. 7, § 110). A contraposição entre capacidade e incapacidade de exercício e entre capacidade e incapacidade de entender e de querer, principalmente nas relações não-patrimoniais, não corresponde à realidade: as capacidades de entender, de escolher, de querer são expressões da gradual evolução da pessoa que, como titular de direitos fundamentais, por definição não transferíveis a terceiros, deve ser colocada na condição de exercê-los paralelamente à sua efetiva idoneidade, não se justificando a presença de obstáculos de direito e de fato que impedem o seu exercício: o gradual processo de maturação do menor leva a um progressivo cumprimento a programática inseparabilidade entre titularidade e exercício nas situações existenciais.

Decorre daí que a emancipação no âmbito civil, instituto jurídico previsto no pelo qual se antecipa a capacidade para o exercício de direitos, extinguindo o poder familiar, de acordo com o artigo 1.635, inciso II, do Código Civil Brasileiro, não tem qualquer efeito jurídico em relação à limitação da proteção integral dos direitos fundamentais do seu titular, em razão da idade.

O reconhecimento da autonomia da criança e do adolescente fica ainda mais claro em muitos direitos previstos na Convenção sobre os Direitos da Criança, como o de expressão e associação, educação ou saúde, que exigem um reconhecimento expresso da sua capacidade para exercê-los diretamente, ao que corresponde os deveres dos pais para orientá-los, de acordo com a evolução da sua capacidade ${ }^{5}$. Para Bruñol (2001, p. 57),

$\mathrm{Na}$ atualidade, em troca, se observa uma tendência em considerar cada vez mais a menoridade não como uma condição da capacidade de agir, mas como uma limitação à capacidade que se fundamente em razão da proteção de seus direitos de acordo com a Convenção, e não somente de uma pessoa ou bem como se estabelecia anteriormente.

\footnotetext{
${ }^{5}$ Recentemente, reconhecendo a autonomia da criança para manifestar sua vontade em relação ao direito à vida e saúde, o Parlamento da Bélgica tornou-se o primeiro país a legalizar a eutanásia infantil sem qualquer limite de idade. Disponível em: http://oglobo.globo.com/mundo/parlamento-belga-aprova-eutanasia-para-criancas-11587473. Acesso em: 24 abril 2014.
} 
Desafios para garantia do direito à participação de crianças e adolescentes no sistema judicial brasileiro

Essa distinção conceitual entre pessoa, personalidade e capacidade repercute até os dias atuais em certa dificuldade para o reconhecimento jurídico de interesses próprios da infância e juventude, de acordo com Paulo Afonso Garrido de Paula (2002, p. 12), em virtude da construção de um sistema onde "a proteção de crianças e adolescentes revelou-se pela tutela do mundo adulto, sendo beneficiários apenas de uma espécie de proteção reflexa, de modo que somente indiretamente vislumbrava-se a proteção jurídica”. Desse ponto de vista,

\begin{abstract}
Ainda que detentores de personalidade jurídica a falta de capacidade de fato ou de exercício importava não conferir direitos à crianças e adolescentes, porquanto materialmente impedidos de exercitá-los, de modo que, os chamados direitos personalíssimos - aqueles que somente podem ser exercitados pelo seu titular ordinariamente escapavam da lógica da construção jurídica (PAULA, 2002, p. 14).
\end{abstract}

Somente com a Constituição Federal de 1988 é que se reconheceu a possibilidade de crianças e adolescentes participarem das relações jurídicas, na qualidade de titulares de direitos fundamentais juridicamente protegidos, como sujeito de direitos, capazes, portanto, para o seu exercício, inclusive pessoal, rompendo com o sistema de proteção indireta dos direitos dos adultos.

Embora até recentemente o Estatuto da Criança e do Adolescente previsse expressamente a obrigatoriedade da manifestação do consentimento do adolescente apenas nas hipóteses de colocação em família substituta (art. $28, \S 2^{\circ}$ e art. $45, \S 2^{\circ}$ ), com a edição da Lei n. 12.010, de 3 de agosto de 2009, foram incluídos como princípios orientadores da aplicação das medidas de proteção, a condição de criança e do adolescente como sujeito de direitos, a obrigatoriedade da informação e a oitiva obrigatória e participação nos processos que lhe digam respeito, implicando num dever de consideração de sua opinião pela autoridade judiciária competente, como reconhecimento e garantia de sua autonomia progressiva para participar das decisões que lhe digam respeito e que repercutam no exercício de seus direitos fundamentais.

Paradoxalmente, o reconhecimento amplo da capacidade do adolescente para sujeitar-se à ação estatal socioeducativa quando acusado da prática de delito, é destacado por PAULA (2002, p. 15):

O mesmo não se diga da capacidade de adquirir ou contrair obrigações, de vez que crianças e adolescentes sempre assumiram o peso das normas de caráter repressivo. A capacidade, portanto, sobre a ótica paradoxal: impossibilitados de exercer 
pessoalmente seus direitos civis, mas reconhecidamente capazes para suportar, inclusive fisicamente, as consequências das reprimendas estatais. Capazes quando em conflito com a lei, quando na qualidade de titulares de interesses juridicamente subordinados, quando considerados insurgentes pelo mundo adulto.

A admissão dessa progressiva capacidade e autonomia como sujeito de medidas de responsabilização socioeducativa em razão da conduta descrita como crime, deve corresponder, portanto, à medidas que também lhe possibilitem o exercício dos direitos de que são titulares, proclamados na Convenção sobre os Direitos da Criança e nos demais instrumentos nacionais e internacionais, prevendo mecanismos efetivos para exercê-los na esfera civil e protegendo-os de todo obstáculo que perturbe o seu exercício legítimo.

Sustenta-se nessa lógica a previsão, no Estatuto da Criança e do Adolescente de garantias individuais que autorizam o exercício pessoal dos direitos atribuídos ao adolescente ao qual é imputada a conduta prevista na lei penal (artigo 111), como a possibilidade de confrontar-se com vítimas e testemunhas (inciso II), o direito de ser ouvido pessoalmente pela autoridade competente (inciso V) e de solicitar a presença dos pais ou responsável em qualquer fase do procedimento (inciso VI), além daqueles específicos quando privados de liberdade, previstos no artigo 124.

A aceitação expressa do adolescente da proposta de remissão, como forma de exclusão ou suspensão do processo e sua revisão (artigo 128), bem como a obrigatoriedade de sua intimação pessoal da sentença que aplicar medida privativa de liberdade, quando poderá manifestar diretamente seu desejo de recorrer (artigo 190), também se coadunam com o reconhecimento da sua autonomia para o exercício pessoal de direitos, exigindo, como condição, que lhe seja garantido o direito de informação, de forma adequada ao seu estágio de desenvolvimento e sua capacidade de compreensão.

O reconhecimento da evolução das capacidades de crianças refere-se, por conseguinte, à capacidade e a possibilidade para exercerem com graus crescentes de independência, os seus direitos frente ao direito-dever dos pais ou adultos responsáveis por sua direção ou orientação. Trata-se de reconhecer às crianças a faculdade de decidir quando e como querem exercer um direito, como também a possibilidade de que a um dado tempo para decidir não exercê-la, com a renúncia de direitos ${ }^{6}$.

\footnotetext{
${ }^{6}$ Para Jaime Couso (2006, p. 151), se não se reconhece ao titular do direito a garantia de renunciar a um determinado direito (mesmo quando seja para resguardar outro mais importante), se submete a pessoa ao perigo permanente de que os outros decidam sua vida, em nome de seus direitos, de acordo com suas preferências. "Assim, o que de fora parecerá a renúncia de um direito, do ponto de vista do titular do direito normalmente se vive como a livre decisão de uma determinada ordem de prioridade de seus interesses, em casos de colisão entre os mesmos".
} 
Desafios para garantia do direito à participação de crianças e adolescentes no sistema judicial brasileiro

Benito Alaez (2003, p. 142) sustenta que um dos elementos centrais do exercício dos direitos fundamentais é o seu exercício autônomo por crianças e adolescentes, advertindo, porém, que as leis permitem que as crianças possam exercer os seus direitos de forma independente (autoexercício) ou por intermédio de representantes (heteroexercício), argumentando que a autonomia progressiva, ou, "a gradual autonomia volitiva da criança" deve ser analisadas à luz de três critérios: idade, maturidade e capacidade de agir, com especial destaque para o último. Deste modo, a capacidade da criança para exercer os seus direitos vai crescendo na medida em que ele se desenvolve, adquirindo gradualmente níveis mais elevados de autonomia e autoproteção.

Deste modo, a direção e orientação dos pais devem levar em consideração a capacidade das crianças e adolescentes exercerem seus direitos por conta própria, que se reduz, progressivamente, na medida em que crianças adquiram competências cada vez maiores, aumentando sua capacidade. Para Eduardo Melo (2011, p. 69), trata-se de uma limitação aos direitos dos pais, mas também do Estado, em relação às crianças e adolescentes, pois, "o reconhecimento da evolução das capacidades de crianças estatui, assim, um novo princípio no Direito Internacional, numa intima correlação entre evolução de capacidades e faculdades de participação".

\section{OITIVA OBRIGATÓRIA, PARTICIPAÇÃO E O DIREITO À INFORMAÇÃO}

O direito segundo o qual a criança deve ser ouvida em qualquer procedimento judicial ou administrativo que lhe diga respeito, previsto no artigo 12.2 da Convenção sobre os Direitos da Criança, insere-se no contexto mais amplo dos direitos de liberdade de opinião (artigo 12.1), expressão (artigo 13), pensamento, consciência e religião (artigo 14), associação e reunião (artigo 15) e informação (artigo 17).

Reconhecendo expressamente que a titularidade de direitos pressupõe as noções de liberdade e autonomia para o seu exercício, como fundamento e conteúdo da própria dignidade da pessoa humana, a admissão da criança e do adolescente como sujeitos de direito implica incluir sua participação nos processos de decisão, constituindo-se como o princípio que reflete a essência da Doutrina da Proteção Integral e a principal inovação da Convenção sobre os Direitos da Criança, rompendo com a ideia de que caberia apenas ao adulto definir o 
que deva ser o seu superior interesse, já que a própria criança está legitimada a falar por si, compreendendo-os a partir de seus próprios interesses. Como ressalta Eduardo Rezende Melo (2011, p. 43),

[...] em termos jurídicos, esta discussão está intimamente relacionada à compreensão da inter-relação entre o direito ao reconhecimento e o princípio da dignidade humana. De fato, é este princípio da dignidade humana que garante os espaços de autonomia e de construção negociada de si aos indivíduos, como decorrência do processo de desconstrução. No caso de crianças e adolescentes, é o que justifica não apenas sua participação, mas também a luta por sua autodeterminação.

Dessa forma, o direito de crianças e adolescentes de livremente expressar suas opiniões e de que as mesmas sejam efetivamente consideradas, estabelece a condição para participação ativa em todas as questões que lhe dizem respeito, no âmbito individual ou coletivo, em especial dentro da família, na escola e nas suas comunidades, consolidando a ideia do protagonismo. "Para tanto, sua efetivação depende de condições existenciais mínimas, integridade física e espiritual e proteção da privacidade do homem” (MELO, 2011, p. 43).

A esse direito, no âmbito processual, a Convenção sobre os Direitos da Criança estabelece no art. 12.2 a obrigação de que seja dada à criança ou ao adolescente, sendo parte ou testemunha, a oportunidade de serem ouvidos em qualquer procedimento judicial ou administrativo que lhes digam respeito, emitindo as suas opiniões sobre os direitos subjetivos que lhe atingem de forma direta ou indireta, que deve ser devidamente considerada, de acordo com as regras processuais do direito nacional.

Constituindo um dos valores fundamentais da Convenção sobre os Direitos da Criança, como assinalado pelo Comitê dos Direitos da Criança na Observação Geral n. 12, de 20 de julho de 2009, o direito de ser escutado enfatiza não somente uma garantia em si, mas, juntamente com os demais princípios gerais estabelecidos pelo órgão (direito a não discriminação, direito à vida e ao desenvolvimento, consideração aos interesses primordiais da criança), constitui critério que deve ser levado em conta para interpretar e respeitar todos os outros direitos.

A relevância desse direito no âmbito internacional também encontra fundamento na Convenção da Haia, de 1996, que dispôs no seu artigo 23, que a sentença estrangeira pode ter seu reconhecimento recusado, quando fixar medidas de proteção sem ter dado à criança a oportunidade de ser ouvida. Esse direito também já constava na Convenção da Haia sobre Sequestro, de 1980 (art. 13), lembrando Jacob Dolinger (2003, p. 129) ainda que "a 
Desafios para garantia do direito à participação de crianças e adolescentes no sistema judicial brasileiro

manifestação da criança foi colocada na Convenção (Haia, de 1996) em termos que a enquadram no princípio de ordem pública no direito internacional privado, constituindo sua falta em sentença estrangeira, obstáculo ao seu reconhecimento".

Antes da Convenção sobre os Direitos da Criança, MONACO (2005, p. 238-239) anota que esse direito de participar nos processos que lhe respeitem esbarrava na legislação da maioria dos Estados-partes que impediam, em suas normas internas, quer a participação da criança como testemunha, quer a sua participação como parte ativa, exigindo-se que se procedesse à substituição processual do infanto - (in = negação; fari = falar) daquele que não fala ou não pode falar - por um de seus genitores, por um tutor ou curador ou por uma instituição. "Desta feita, as legislações nacionais quase unanimemente tiveram de ser alteradas após a ratificação da Convenção, permitindo-se o acesso das crianças aos tribunais para emitir sua opinião".

A fixação de critérios etários para definir quando uma criança é capaz de exercer pessoalmente seus direitos não é pacífica na doutrina, considerando os riscos de rigidez na aplicação destes parâmetros, sem considerar que as crianças têm experiências de vida e formas de expressar diferente. "Nem todas as crianças são iguais, daí a necessidade de se estabelecer normas flexíveis que permitem aos operadores ponderar caso a caso as condições da fala das crianças de acordo com a sua idade, mas também de sua maturidade. Isso nos leva à necessidade de reforçar as competências dos operadores do sistema para ouvir as crianças, especialmente as menores" (PAVEZ; CAMUS, 2011, p. 183-184).

Por isso, de acordo com Jaime Couso (2006, p. 153), a previsão da Convenção sobre os Direitos da Criança garantindo o direito "à criança que estiver capacitada a formular seus próprios juízos" deve ser entendida em um sentido amplo, "abrangendo toda criança que possa ter algo relevante a comunicar sobre um assunto que a afetará, incluindo através de formas não verbais".

O autor cita ainda a fórmula da Children's Act inglesa de 1989, que considera especialmente feliz, ao referir-se a "desejos e sentimentos" da criança, incluindo não somente aos desejos formulados em forma discursiva, mas também a sentimentos expressados de outra forma, o que é muito importante para crianças com menores competências linguísticas ou crianças que em certas circunstâncias não podem verbalizar, mas demonstram de formas perceptíveis (às vezes, com veemência), seus sentimentos positivos ou negativos diante de 
certas opções. “A 'escuta' desses conteúdos não discursivos exige dar tempo à criança e contar com uma competência especial por parte de que consulta sua 'opinião"” (COUSO, 2006, p. 153).

Identificando quatro níveis de participação no processo decisório, Gerison Lansdown (2005, p. 20) afirma que o exercício desse direito implica, por um lado, na garantia, para sua plena realização, do direito à informação e expressão de sua opinião informada, e, por outro, que a criança tenha efetividade essa capacidade, deseje exercê-la e tenha oportunidade de fazê-lo. Para o autor, “o resultado, será uma decisão tomada por adultos, mas informada e influenciada pelas opiniões da criança”.

Por outro lado, se a Convenção sobre os Direitos da Criança limita o exercício do direito de expressar sua opinião em razão da maturidade e da capacidade da criança em formar um juízo próprio, o seu desenvolvimento emocional ou do seu interesse superior, somente será possível compatibilizar o seu exercício com a etapa de crescimento pela qual uma criança esteja atravessando, orientando-se pela máxima satisfação dos direitos da criança estabelecida pela Doutrina da Proteção Integral, pois, como assinala Mary Bellof (2008, p. 14),

Na nova concepção se trata de uma interpelação dos adultos, não mais uma autorização para limitar os direitos das crianças. São os adultos os responsáveis por realizar os arranjos institucionais e condições necessárias para que em cada momento as crianças possam exercer seus direitos reconhecidos pelo tratado.

E ainda:

De todos os direitos, um que estrutura a lógica da proteção integral é o direito da
criança de ser ouvido e sua opinião ser considerada. Se passa de uma concepção de
exclusão da voz do menor, onde as crianças, como incapazes, não tinham nada que
dizer, a outra mais próxima a situação ideal do diálogo em que participam todos os
cidadãos. [...] a democracia necessita que as crianças opinem e participem. Como
fazê-lo é responsabilidade dos adultos, que devem projetar arranjos institucionais
que permitam que a opinião das crianças sejam consideradas (2008, p. 36).

Essa consideração acerca da limitação decorrente das condições de maturidade para formar juízo próprio, de acordo com a Observação Geral n. 12 do Comitê dos Direitos da Criança, estabelece, todavia, que os Estados não podem partir da premissa de que uma criança é incapaz de expressar suas opiniões. Ao contrário, devem partir da suposição de que a criança tem condições de expressar suas opiniões e reconhecer que tem direito a expressá-las, não exigindo que lhe caiba primeiro provar que tem essa capacidade. Tal condição tampouco se confunde com a capacidade civil ou processual para o exercício de direitos, que, como 
Desafios para garantia do direito à participação de crianças e adolescentes no sistema judicial brasileiro

visto, estabelece limitações à autonomia da criança e do adolescente que se aplicam apenas às situações jurídicas patrimoniais.

Ao estabelecer que a opinião da criança e do adolescente deverá ser devidamente considerada pela autoridade competente, o princípio deixa claro ainda que não é a idade em si mesma que determinará a validade de suas opiniões, já que os níveis de compreensão não estão ligados de maneira uniforme à sua idade biológica, mas devem ser avaliadas mediante exame do caso em concreto, pois outras circunstâncias podem contribuir para avaliar sua capacidade de formar sua opinião, como o próprio ambiente familiar, cultural e social, além do nível de informação e apoio recebidos.

No plano nacional, mesmo com a ratificação da Convenção sobre os Direitos da Criança em 1990, o Estatuto da Criança e do Adolescente foi limitado em relação à garantia do direito à participação, previsto no artigo 16 como um aspecto do direito à liberdade, correspondente ao direito de opinião e expressão (inciso I), de participar na vida familiar e comunitária (inciso V) e política, na forma da lei (inciso VI) e em relação ao direito à educação para contestar os critérios avaliativos e participar em entidades estudantis (art. 53).

Ainda que não se tenha estabelecido, genericamente, qualquer obrigação correlata à família, à sociedade e ao poder público no sentido de viabilizar os instrumentos efetivos para sua escuta e para que sejam efetivamente consideradas nas decisões, essa imposição foi prevista expressamente apenas nos casos de colocação em família substituta, estabelecendo que a criança ou adolescente será previamente ouvido e terá a opinião "devidamente considerada" (art. 28, § $1^{\circ}$ ); acrescentando que, nos casos de adoção de adolescente, "será necessário seu consentimento, colhido em audiência" (art. 28, $\S 2^{\circ}$ ). Também nos procedimentos de apuração de ato infracional o direito de ser ouvido pela autoridade competente é assegurado expressamente como garantia processual (art. 111, V).

Apenas em 2009, com a edição da Lei n. 12.010 foi acrescentado ao Estatuto da Criança e do Adolescente o princípio da "oitiva obrigatória e participação" da criança e do adolescente nos atos e na definição da medida de promoção dos direitos e de proteção, sendo sua opinião devidamente considerada pela autoridade judiciária competente (art. 100, parágrafo único, inciso XII). 
Alterando o texto do artigo 28 antes citado $^{7}$, a nova legislação reforçou como condição da participação às hipóteses em que "seja possível", prevendo a oitiva por equipe interprofissional, mantendo-se o critério etário da obrigatoriedade do consentimento expresso apenas no caso de adoção.

A expressão "sempre que possível", por sua vez, deve ser entendida não no sentido de atribuir uma faculdade ou discricionariedade ao juiz, de ouvir ou não a criança, mas como uma impossibilidade da criança, no caso de, por exemplo, não querer ser ouvida.

Por esse motivo, para a criança ou adolescente, expressar sua opinião deve ser sempre uma opção, não uma obrigação, sem compromisso de atender a demanda exposta, cabendo às autoridades e responsáveis assegurar que recebam toda a informação e assessoramento necessários para tomar uma decisão que favoreça seu interesse superior, como também prevê expressamente o princípio previsto no inciso XI, do parágrafo único do artigo 100, do Estatuto da Criança e do Adolescente.

Isso não implica, obviamente, em um conhecimento exaustivo de todos os aspectos do assunto que o afeta, mas uma compreensão suficiente sobre o assunto, opções e possíveis decisões, especialmente quanto às consequências negativas, como quando se trata de crianças muito pequenas, vítima ou testemunha de crimes, em formato e linguagem adequados à sua idade e capacidade de entendimento, para que seja capaz de manifestar suas opiniões.

\begin{abstract}
Resgatá-la para a condição de sujeito, com desejos, expectativas e relações estabelecidas, é de fundamental importância para preservar e fortalecer sua subjetividade e dignidade. Este resgate só se torna possível ao considerar-se sua fala, que pode se dar com ou sem o uso da palavra falada. Fazer a oitiva da criança não significa utilizá-la como testemunha de um dos elementos do casal, o que a dividiria e criaria conflitos desnecessários, tendo em vista que ela mantém uma relação afetiva com cada um dos pais. Significa sim considerar, em seu discurso explícito e/ou implícito, com qual dos dois houve a criação de um vínculo afetivo mais estável, seguro e satisfatório, que permita a continuidade de seu desenvolvimento integral de forma mais adequada. Auxiliá-la a manter sua subjetividade e dignidade, considerando-a como um sujeito em desenvolvimento, mas que no desenvolvimento precedente construiu sua própria história. Respeitar sua dignidade (MONACO; CAMPOS, 2005).
\end{abstract}

Ainda que compreendido o direito à participação como direito à própria liberdade de expressão, cujo conteúdo está relacionado com o direito a ter e expressar opiniões e a solicitar e receber informações por qualquer meio, o princípio procedimental que assegura o direito de

\footnotetext{
${ }^{7}$ Art. $28[\ldots]$

$\S 1^{\circ}$ Sempre que possível, a criança ou o adolescente será previamente ouvido por equipe interprofissional, respeitado seu estágio de desenvolvimento e grau de compreensão sobre as implicações da medida, e terá sua opinião devidamente considerada.
}

RJurFA7, Fortaleza, v. 12, n. 2, p. 10-32, jul./dez. 2015 
Desafios para garantia do direito à participação de crianças e adolescentes no sistema judicial brasileiro

escuta de crianças e adolescentes constitui, desse modo, obrigação específica no sentido de que sejam previstos mecanismos necessários para facilitar a sua participação ativa em todas as medidas que lhes afetem e na adoção de decisões que as tenham em consideração. A oitiva da criança, todavia, "não significa que o Juiz deva seguir o que esta sugere, mas deve levar em conta que a criança e o adolescente podem ter vontade de verbalizar o que se passa com eles, ou ainda, que necessitem tirar dúvidas sobre as situações que os envolvem” (BRITO, 1999, p. 79).

Como testemunha em processos judiciais ${ }^{8}$, a participação de crianças e adolescentes também deve ser analisada no contexto de seu superior interesse e realizada de forma protegida, devendo-lhe ser disponibilizado recursos médicos, psicológicos e demais acolhimentos que se fizerem necessários, a fim de evitar a sua revitimização no depoimento forense, pois, como assinala MONACO (2005, p. 242-243),

\begin{abstract}
Não se deve permitir, ao que parece, a indicação da criança como testemunha por uma das partes, ou seja, por um de seus pais ou parentes, sob pena de a criança se sentir envolvida de forma que se mostra pouco conveniente. É interessante notar que a criança que comparece ao processo solicitando sua oitiva não é parte interveniente no processo, pelo que não poderá recorrer dessa decisão em hipótese de ver indeferida sua pretensão.
\end{abstract}

E conclui:

Acredita-se que esta forma de se encarar esse direito de participar das decisões relevantes para a continuidade da vida das crianças é uma conquista que não pode ser olvidada, diminuída ou restringida. Por outro lado, garantir a participação da criança não pode nem constituir um ônus imposto à criança (daí o critério da maturidade se mostrar o mais adequado), bem como representar a imposição de uma decisão por parte do jovem.

Nas situações em que presenciam ou são vítimas de situações de crime, a proteção das crianças e adolescentes em investigações e processos judiciais tem resultado em mudanças importantes na prática judicial de diversos países, incluindo a adoção de programas de preparação individualizada para compreenderem melhor os procedimentos e as terminologias

\footnotetext{
${ }^{8}$ Em relação à criança vítima ou testemunha de crimes, o Conselho Econômico e Social da Organização das Nações Unidas (ECOSOC) editou a Resolução 20, de 22 de julho de 2005, intitulada "Guidelines on Justice in Matters involving Child Victims and Witnesses of Crime". Disponível em: www.un.org/ecosoc/docs/2005/Resolution\%202005-20.pdf.
} 
empregadas no sistema judicial, bem como a aceitação como prova dos testemunhos prestados fora do tribunal.

De acordo com as experiências relatadas por Benedito Rodrigues dos Santos e Itamar Batista Gonçalves (2009, p. 25-26), considerando o receio que muitas crianças expressam de depor e a ansiedade decorrente da pouca compreensão sobre o processo judicial, no comparecimento à Justiça,

\begin{abstract}
Para poupar as crianças, em alguns países, as pequenas (menores de 14 anos) raramente comparecem ao tribunal durante as audiências ou julgamentos. Em Israel, o entrevistador forense depõe no lugar da criança e relata o que ela disse. Na Inglaterra, a promotoria de justiça apresenta o vídeo da entrevista forense ao tribunal. A inquirição da defesa é conduzida pelo promotor de justiça em uma sala especial do tribunal, na qual o depoimento da criança pode ser transmitido por closed-circuit television (CCTV) [circuito fechado de televisão] aos presentes na sala de julgamento. Na Noruega, policiais especialmente treinados para fins de investigação conduzem a entrevista da criança, que é realizada em uma sala equipada com espelhos unidirecionais. $\mathrm{O}$ juiz, o promotor de justiça e o advogado de defesa assistem e escutam a entrevista atrás do espelho. Eles podem fazer perguntas ao entrevistador durante o procedimento, que funciona como uma inquirição direta da criança.
\end{abstract}

No Brasil, a partir da experiência do projeto denominado "Depoimento sem Dano", implantado em 1993 pela Vara da Infância e Juventude de Porto Alegre, a escuta protegida de crianças e adolescentes vítimas ou testemunhas de crimes, especialmente os sexuais, foi objeto de recomendação aos tribunais pelo Conselho Nacional de Justiça no sentido de viabilizar a sua instalação em todos os estados, cujos serviços deverão estar aptos a garantir a sua proteção durante e após o procedimento judicial.

Ainda que não estejam diretamente relacionados como parte ou testemunha nos processos judiciais, em todas as ações que envolvam direta ou indiretamente os direitos de crianças e adolescentes, seja no âmbito civil, como divórcio e separação, no âmbito penal, como vítimas, ou, nos procedimentos para apuração dos atos infracionais, deve ser obrigatoriamente garantido o seu direito de ser ouvido e participar, cabendo à autoridade judiciária indicar na decisão a ser tomada os aspectos relacionados à opinião manifestada, expondo as razões que justificaram eventualmente a sua não observância, sob pena de violação do princípio processual que decorre da sua própria condição de sujeito de direitos fundamentais. "A fala da criança deve ser, portanto, a soberana das provas e essencial na instrução dos processos que envolvam seus interesses" (SIMAS, 2008, p. 611).

Essa obrigação estende-se inclusive aos processos cíveis ou penais em que haja composição pelas partes, tratando-se, por exemplo, de separações consensuais ou 
Desafios para garantia do direito à participação de crianças e adolescentes no sistema judicial brasileiro

procedimentos de mediação ou arbitragem, que deverá considerar os interesses da criança ou adolescente diretamente envolvidos oportunizando-lhe o exercício do direito de manifestar diretamente sua opinião, em detrimento da celeridade processual e dos interesses de seus pais ou representantes, mesmo quando não haja conflito de interesses aparente.

Em relação aos requisitos básicos para a observância do direito da criança e do adolescente de serem escutados, Tânia da Silva Pereira (2008, p. 30-31) indica algumas condições objetivas que podem contribuir para o seu exercício perante os juízes e tribunais:

1. adaptar os procedimentos com vistas a garantir a manifestação autêntica da vontade da criança ou do adolescente;

2. criar condições que facilitem a expressão espontânea da criança, evitando situações de angústia e linguagem técnicas incompreensíveis;

3. favorecer a intervenção de profissionais especializados que possam interpretar, de maneira apropriada, a palavra da criança e do adolescente, permitindo-lhe expressar seus interesses e conflitos com maior liberdade;

4. fornecer à criança e ao jovem todas as informações relativas à sua situação e ao assunto sobre o qual deverá emitir sua opinião;

5. não forçá-los a se exprimirem ou se manifestarem caso não estiverem preparados;

6. convocá-los a participar dos procedimentos de mediação familiar destinados a solucionar conflitos que envolvam sua pessoa e seus interesses;

7. considerar seus sentimentos e pensamentos na solução dos conflitos que lhes digam respeito;

8. assumir a "Curadoria Especial" como alternativa de interferir nos procedimentos para fazer valer os direitos de seu representado;

9. evitar a convocação da criança e do adolescente como testemunha de um dos pais contra o outro; sua oitiva deve representar uma forma de expressar sua opinião e a preferência sobre a situação conflitante; tal depoimento nunca deverá ser prestado na presença dos pais.

Além destes, na Observação Geral n. 12 do Comitê dos Direitos da Criança também são destacadas as condições para que os procedimentos sejam seguros e se adotem todas as precauções para redução dos riscos ou consequências negativas decorrentes de sua participação, bem como para que sejam responsáveis, mediante o compromisso de que a 
criança e o adolescente sejam informados sobre a forma pela qual sua participação influenciou na decisão, oportunizando-lhe a possibilidade de rejeitar as conclusões e recorrer.

Embora que não esteja previsto procedimento específico na legislação nacional, do ponto de vista da garantia constitucional de acesso à Justiça, deve ser assegurado à criança e ao adolescente ainda o acesso direto e pessoal a todos os órgãos administrativos e judiciais, incluindo o Poder Judiciário, o Ministério Público e à Defensoria Pública, como também estabelece o artigo 141, do Estatuto da Criança e do Adolescente, correspondendo assim, à obrigação das instituições respectivas de estruturar serviços, ambientes e a capacitação necessárias para o seu atendimento, já que não se deve interpretar que a sua falta restrinja ou impeça o exercício deste direito fundamental.

A fragilidade que se deduz das eventuais limitações relativas à falta de estrutura e recursos pessoais dos profissionais para efetivação dos procedimentos de escuta obrigatória e garantia do direito à participação da criança ou adolescente não exime o Poder Executivo, em relação aos órgãos administrativos, o Poder Judiciário, assim como as demais instituições que compõe o Sistema de Justiça, do dever legal de seu cumprimento, atualmente restritos a acontecimentos e enfoques meramente simbólicos limitados às situações expressamente previstas no Estatuto da Criança e do Adolescente nas quais o seu consentimento constitua-se como condição de validade do ato jurídico.

Como salienta Eduardo Rezende Melo (2011, p. 70), dessas circunstâncias decorre que,

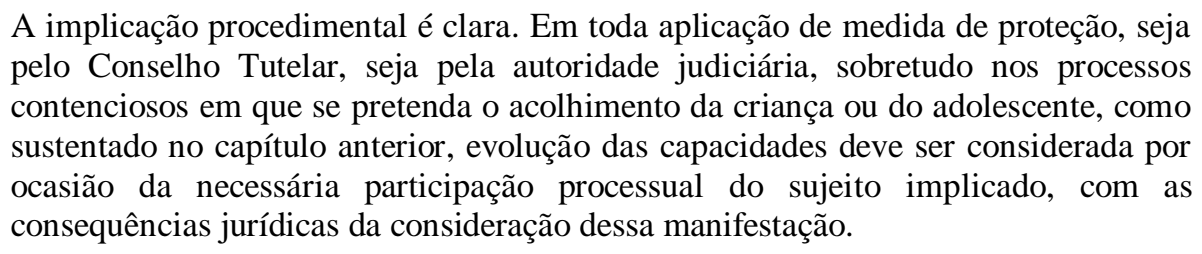

A falta de regras procedimentais específicas para a garantia do direito de escuta de crianças e adolescentes em processos judiciais reforça a resistência dos profissionais para sua concretização, na medida em que, mesmo enfrentando dificuldades, os métodos atuais para a definição das questões que envolvam crianças e jovens ainda não encontraram parâmetros seguros para priorizar os interesses desses novos sujeitos de direitos no âmbito do processo, a fim de assegurar que seus interesses sejam levados em consideração, o que não autoriza, todavia, a sua inobservância.

Embora a Lei n. 12.010/2009 tenha representado avanço prevendo expressamente como princípio a "oitiva obrigatória e participação" de crianças e adolescentes nas decisões que os 
Desafios para garantia do direito à participação de crianças e adolescentes no sistema judicial brasileiro

afetem (art. 100, parágrafo único, inciso XII), pouco se observa em termos efetivos no sentido de sua implementação no cotidiano forense, especialmente nos processos de natureza protetiva junto à Justiça especializada e naqueles que as envolvem e que tramitam nas varas de família, diante da regra de competência concorrente, de acordo com o artigo 148, parágrafo único do Estatuto da Criança e do Adolescente.

Ainda que o princípio tenha aplicação expressa às medidas de proteção (Título II, Capítulo II), não se pode negar que, como consectário da proteção integral e da condição de crianças e adolescentes como sujeito de direitos, tem natureza cogente em todos os demais processos judiciais que os envolvam direta ou indiretamente, especialmente naqueles em que haja restrição aos seus direitos, como nos casos de afastamento do convívio familiar, alteração da sua guarda pelos genitores ou por terceiros, incluindo procedimentos administrativos perante o Conselho Tutelar e também nas hipóteses em que a criança ou adolescente figuram como testemunhas ou vítimas de crime.

Tratando-se de medidas relacionadas à convivência familiar, a jurisprudência brasileira, todavia, ainda não encontrou parâmetros seguros para a garantia desse direito, pois, embora reconheça a necessidade de participação de crianças e adolescentes na definição da providência jurisdicional que atenda ao seu superior interesse, não indica os critérios que determinam quando sua oitiva deve ser realizada direta e pessoalmente perante o juízo, as razões que justificam a mediação de sua voz por intermédio de relatórios e estudos realizados pela equipe interprofissional, e, tampouco, como é efetivada a sua defesa.

Nos casos em que a criança é ouvida diretamente perante o juízo ou nas decisões homologatórias de acordo celebrado entre as partes, que extinguem o processo com julgamento do mérito, sequer se pode inferir como vem sendo realizada essa escuta, se há determinação de critério etário e como são ouvidas crianças muito pequenas, se a criança recebe a informação sobre o processo e suas consequências, dentre outros aspectos.

Como um dos pilares fundamentais da nova concepção da criança como sujeito de direitos, o direito da criança a ser ouvida refere-se, em primeiro lugar, a uma manifestação do direito à liberdade expressão e de pensamento, correspondendo à obrigação dos Estados em regular esse direito, estabelecendo critérios interpretativos para garantir a sua efetividade na tomada de decisões que possam afetar sua vida. 
Nesse sentido, a Observação Geral n. 12, do Comitê sobre os Direitos da Criança, assinala expressamente e postula que se trata de uma participação que não se não se esgota em uma ou duas ações específicas, mas deve ser entendida como um processo permanente. "Ouvir as crianças e facilitar a sua participação não deve ser uma dificuldade extra, mas uma parte fundamental de um sistema efetivamente reconhece e protege os seus direitos" (PAVEZ; CAMUS, 2011, p. 180).

No âmbito nacional, embora a Lei n. 12.010/2009 tenha expressamente previsto como princípio regente a obrigatoriedade da informação, pelo qual "a criança e o adolescente, respeitado seu estágio de desenvolvimento e capacidade de compreensão, seus pais ou responsável devem ser informados dos seus direitos, dos motivos que determinaram a intervenção e da forma como esta se processa" (art. 100, parágrafo único, inciso XI, do Estatuto da Criança e do Adolescente), não se pode aferir, do ponto de vista procedimental, os vários aspectos relacionados a esse direito, desde o momento em que se decide qual, ou quais, informações devem ser repassadas para promover a oitiva da criança ou adolescente, quem ouvirá a criança e de que forma, como essa participação pode influir na decisão, dentre outros.

Dessa forma, caberá aos adultos e às instituições desenvolverem as habilidades e competências para a promoção desse direito, com necessárias implicações procedimentais, como destaca Eduardo Rezende Melo (2011, p. 47), para quem,

\begin{abstract}
Melhora-se a capacidade do exercício de competências aumentando ativos pessoais de crianças e adolescentes para lidar com o sistema ou fazendo com que as escolhas dentro do sistema se tornem menos irreversíveis. Isso se faz pela diminuição de riscos com as escolhas, seja pelo controle do ambiente ao nível coletivo, aumentando a competência individual para decidir. [...] É esta imposição de esforço ativo por parte de todo e qualquer adulto para que a criança ou adolescente tenha condições de exercer essa competência intelectual ou jurídica, que dita o art. 12 da Convenção sobre os Direitos da Criança. Se toda criança e adolescente tem garantido o direito à expressão de seus juízos e de serem estes devidamente considerados em todos os assuntos relacionados à sua vida, incumbe aos adultos encontrar critérios cognitivos e práticos que lhes permitam posicionar-se.
\end{abstract}

A adoção de uma medida que afeta a criança ou o adolescente, depois de haver considerado sua opinião, em um sentido substancial, será uma decisão diferente, de maior qualidade, já que fundamentada no respeito à sua dignidade e autonomia.

\footnotetext{
Dito em forma negativa, uma decisão sobre um assunto relevante na vida da criança, que se adote sem permitir a sua participação na produção da decisão, implica um ato de extrema violência: a violenta experiência de que sua vida seja decidida por pessoas que não o conhecem e que não demonstram ter interesse em saber o que se passa (COUSO, 2006, p. 154).
} 
Desafios para garantia do direito à participação de crianças e adolescentes no sistema judicial brasileiro

Essa necessária diferença na consideração de crianças e adolescentes como sujeitos de direitos justifica assim a implementação de esforços relacionados à política judiciária que devem ser direcionados aos investimentos necessários para que os operadores possam dispor de tempo e habilidades para dar efetiva participação à criança na instrução processual e na tomada de decisões.

Somente desse modo é se poderá dar concretude ao princípio da efetividade, consagrado no $\operatorname{artigo} 4^{\circ}$ da Convenção sobre os Direitos da Criança, que consiste na obrigação dos Estados em adotar todas as medidas administrativas, legislativas e de qualquer outra índole para dar efetividade aos direitos de crianças e adolescentes.

\section{CONCLUSÃO}

O paradigma da "Doutrina da Proteção Integral", instaurado a partir da Convenção sobre os Direitos da Criança, possibilitou repensar profundamente o sentido das legislações para a infância, transformando-as em instrumentos eficazes de defesa e promoção dos direitos humanos específicos de todas as crianças e adolescentes.

A nova postura exigida, a partir de sua nova condição como sujeitos de direitos, demanda o reordenamento das práticas e arranjos institucionais para que seja assegurado o seu direito a serem ouvidos em todos os processos que lhes afetem, e que sua opinião seja devidamente considerada, respeitada a sua capacidade e o seu estágio de desenvolvimento.

Nesse sentido, o reconhecimento da autonomia progressiva de crianças e adolescentes para o exercício pessoal de seus direitos personalíssimos, não vinculada à concepção que a limita de acordo com os critérios relativos à capacidade civil, bem como a garantia do seu direito à informação, liberdade de expressão e de opinião e de participação, devem orientar as ações a serem implementadas.

A percepção do contexto nacional mostra que estamos muito longe da garantia desse direito no país, onde ainda são incipientes as iniciativas e esforços para promoção da participação de crianças e adolescentes, que, majoritariamente não são ouvidas no âmbito da família, nas instituições onde se inserem, como escolas, organizações não governamentais, na 
organização urbana dos municípios e das políticas públicas, e, especialmente, nas instituições do Sistema de Justiça.

A despeito de alguns progressos, poucos debates e reflexões têm sido realizados no país acerca da necessidade do Sistema de Justiça repensar as práticas judiciárias que, a despeito da necessidade de resolução rápida das lides, ignoram a importância opinião da criança e do adolescente em relação às decisões que os afetem, embora não se possa desconsiderar os avanços realizados a partir da iniciativa e do esforço pessoal de magistrados, promotores de Justiça e defensores públicos em vários estados brasileiros voltados à superação do paradigma da incapacidade.

A necessidade de detalhamento do conteúdo referente à garantia do direito à participação, com o estabelecimento de regras procedimentais explícitas nos procedimentos administrativos e judiciais, afigura-se imprescindível no país para suprir o déficit correspondente à plena incorporação da Convenção sobre os Direitos da Criança nas práticas e na cultura jurídica.

O aprimoramento da política judiciária e o estabelecimento de instâncias judiciais diferenciadas, além de contribuir para a gestão da organização judiciária, representará efetivo avanço na implementação da Doutrina da Proteção Integral e na superação do paradigma da incapacidade, visando consolidar a participação de crianças e adolescentes nos processos como sujeitos titulares de direitos e garantias, tanto nos conflitos de família como nos procedimentos para proteção de seus direitos.

\section{REFERÊNCIAS}

ALAEZ, Benito. Minoría de edad y derechos fundamentales. Madrid: Editorial Tecnos, 2003.

BELOFF, Mary. Los derechos del niño en el sistema interamericano. Ciudad Antónoma de Buenos Aires: Del Puerto, 2008.

BRUÑOL, Miguel Cillero. El interes superior del niño em el marco de la Convención Internacional sobre los Derechos del Niño. In: MÉNDEZ, Emilio Garcia; BELOFF, Mary (org.). Infancia, Ley y Democracia en América Latina. 2. ed. Tomo 1. Santa Fe de Bogotá: Editorial Temis, 1999. 
Desafios para garantia do direito à participação de crianças e adolescentes no sistema judicial brasileiro

Los Derechos Del Niño: De la proclamación a la protección efectiva. In: Justicia y Derechos Del Niño. Número 3. Buenos Aires: UNICEF, 2001.

COUSO, Jaime. El niño como sujeto de derechos y la nueva Justicia de Familia. Interés superior del niño, autonomía progresiva y derecho a ser oído. Revista de Derechos del Niño, Números 3 y 4. Santiago: Universidad Diego Portales y UNICEF, 2006.

DOLINGER, Jacob. Direito Internacional Privado: a proteção da criança no direito internacional. Rio de Janeiro: Renovar, 2003.

LANSDOWN, Gerison. La evolución de las facultades del niño. Florença: Centro de Investigaciones Innocenti de UNICEF, 2005. Disponível em: http://www.unicef.org/lac/evolving-spa.pdf. Acesso em 13 jul. 2014.

MELO, Eduardo Rezende. Crianças e adolescentes em situação de rua: direitos humanos e justiça. São Paulo: Malheiros, 2011.

MONACO, Gustavo Ferraz de Campos. A proteção da criança no cenário internacional. Belo Horizonte: Del Rey, 2005.

; CAMPOS, Maria Luiza Ferraz de. O direito de audição de crianças e jovens em processo de regulação do exercício do poder Familiar. Revista Brasileira de Direito de Família, Número 7 (32), 2005, p. 5-19.

ORGANIZAÇÃO DAS NAÇÕES UNIDAS (ONU). Comitê dos Direitos da Criança. Observación General n. 12, de 20 de julho de 2009. El derecho del niño a ser escuchado. Disponível em: http://tbinternet.ohchr.org/_layouts/treatybodyexternal/Download.aspx?symbolno=CRC\%2fC \%2fGC\%2f12\&Lang=en Acesso em: 12 mai. 2014.

PAUlA, Paulo Afonso Garrido de. Direito da Criança e do Adolescente e Tutela Jurisdicional Diferenciada. São Paulo: Revista dos Tribunais, 2002.

PAVEZ, Macarena Vargas; CAMUS Paula Correa. La voz de los niños en la Justicia de Familia de Chile. Revista Ius et Praxis, Universidad de Talca - Facultad de Ciencias Jurídicas y Sociales. Ano 17, no 1, 2011, p. 177 - 204.

PEREIRA, Tânia da Silva; OLIVEIRA, Guilherme de (Coord.). O Cuidado como Valor Jurídico. Rio de Janeiro: Forense, 2008.

PERLINGIERI, Pietro. Perfis do direito civil. 3. ed. Rio de Janeiro: Renovar, 2007. 
SANCHES, Helen Crystine Corrêa. Da vara de menores à vara da infância e juventude: desafios para a proteção integral dos direitos de crianças e adolescentes no Sistema de Justiça brasileiro. Tese (Doutorado em Direito). Universidade Federal de Santa Catarina, Florianópolis, 2014.

SANTOS, Benedito Rodrigues dos; GONÇALVES, Itamar Batista (Coord.) Depoimento sem medo. Culturas e práticas não revitimizantes. Uma cartografia das experiências de tomada de depoimento especial de crianças e adolescentes. 2. ed. São Paulo: Childhood Brasil (Instituto WCF-Brasil), 2009.

SIMAS, Ulisses Fialho. O melhor interesse da criança e do adolescente em face das regras processuais e procedimentos cíveis da Lei n. 8.069/90. In: PEREIRA, Tânia da Silva (org.). O Melhor Interesse da Criança: um debate interdisciplinar. Rio de Janeiro: Renovar, 1999. TEIXEIRA, Ana Carolina Brochado et al. O cuidado com o menor de idade na observância de sua vontade. In: PEREIRA, Tânia da Silva; OLIVEIRA, Guilherme de (Coord.). O Cuidado como Valor Jurídico. Rio de Janeiro: Forense, 2008.

VERONESE, Josiane Rose Petry. Os direitos da criança e do adolescente. São Paulo: LTr, 1999.

Direito Penal Juvenil e Responsabilização Estatutária: perspectivas aproximativas e/ou distanciadoras. Estágio Pós-Doutoral em Serviço Social. Pontifícia Universidade Católica do Rio Grande do Sul, Porto Alegre, 2012.

VILLAVICENCIO, Luis; MILLÁN, Patricio. La representación de niños, niñas y adolescentes en los procedimientos para la adopción de medidas de proteccíon. Revista de Derechos Del Niño, Número 1. Santiago: UNICEF, 2002, p. 41-91. 